\title{
Migrações, Fronteiras e Territórios: $O$ caso de famílias Manchineri na Tríplice BR-BOL-PE ${ }^{1}{ }^{2}$
}

Migration, borders and territories: the case of Manchineri families in the Triple BR-BOL-PE

\begin{abstract}
Alessandra Severino da Silva Manchinery Mestranda em Geografia na Universidade Federal de Rondônia - UNIR, Pesquisadora do Grupo de Pesquisa Geografia, Natureza e Territorialidades Humanas - GENTEH/UNIR, Brasil amanchinery@gmail.com
\end{abstract}

Suzanna Dourado da Silva Doutoranda em Geografia/UNIR, Pesquisadora do GENTEH/UNIR, Brasil suzannadourado@gmail.com

Adnilson de Almeida Silva Doutor em Geografia, docente do Departamento e Programa de Pós-Graduação em Geografia PPGG/UNIR e Pesquisador do GENTEH/UNIR, Brasil

adnilson@unir.br

\begin{abstract}
Resumo
O trabalho relata a vida de famílias migrantes do povo Manchineri, com destaque, principalmente às redes de migrações, às fronteiras e os territórios. Intencionalmente mostramos como famílias de indígenas que migraram foram obrigadas a constituir e construir novas características de sobrevivência no mundo ocidental, bem como novas territorialidades em distintos territórios em novas zonas e categorias, e se "distribuírem" em recintos desconhecidos e invisíveis. Desta maneira o objetivo foi compreender como tem se perpetuado os circuitos migratórios, suas diversas territorialidades em área de tríplice fronteira, como também seu retorno para as aldeias, ou seja, suas terras de origem. Assim, as migrações indígenas são mostradas de duas maneiras, as circulares e as lineares. As circulares ocorrem quando a família se retira de sua terra de origem e retorna; já as lineares quando a família afasta de sua terra de origem e não retorna, porém continua com a redes de parentesco e amizade com o local de origem. Esses dois tipos de migrações são as mais básicas para a compreensão do que é a mobilidade indígena, seja ela "forçada" ou livre. O que devemos levar em consideração é a hora de migrar, o fato e o histórico da família. A pretensão nesta ocasião é garantir as vozes dos entrevistados durante todo o processo de escrita e compreensão do artigo. O povo Manchineri vive no Departamento de Pando (BOL), Departamento de Madre Dios (PE) e em território brasileiro na cidade de Assis Brasil, Estado do Acre, na TI Mamoadate, TI Cabeceira do Acre e Seringal Guanabara, e outros localizados em centros urbanos nos três países. Como caminho metodológico utilizamos a história oral, as entrevistas e a experiência de vida de cada entrevistado, porque assim participamos de sua vida diária e realidades de sua vivência. $\mathrm{O}$ intuito assim é inserir estudo das migrações indígenas, fronteiras indígenas e territórios indígenas nas discussões da

\footnotetext{
${ }^{1}$ Apoio: Projeto "Geografia e marcadores territoriais: sentidos e representações socioculturais amazônicas", Chamada Edital PQR/FAPERO nº 003/2017. A autora principal é bolsista do Conselho Nacional de Desenvolvimento em Pesquisa $-\mathrm{CNPq}$.

${ }^{2} \mathrm{O}$ presente foi revisto e possui algumas modificações textuais foi originalmente publicado e selecionado no III Simpósio Internacional de Geografia Política e Territórios Transfronteiriços (GEOTRANS) e V Simpósio Nacional de Geografia Política, Território e Poder (GEOSIMPOSIO) "Conflitos e desigualdades territorial na sociedade contemporânea", em Alfenas - Minas Gerais, em junho de 2019, Alfenas, para compor a Revista Caderno de Geografia da PUC-MG.
} 
Geografia contemporânea com um meio de contribuir com novas discussões na academia e fora da academia, somente assim trabalhamos uma discussão intercultural em âmbito acadêmico e para toda a compreensão da sociedade civil. Neste sentido, levamos em consideração que os estudos sobre questões indígenas precisam com urgência ganhar destaque na atual conjuntura da Geografia Política, já que suas terras indígenas estão sempre em disputa no âmbito por exploração de seus recursos naturais. Essa cena nos mostra o quão esses povos vivem sempre em luta para garantir seu modo de vida e sua terra tradicional, já que hoje foi garantido um enorme retrocesso nas conquistas e direitos dos povos Indígenas. Faz-se necessário fazer esse estudo sobre migrações indígenas dentro da geografia para aproximar essa ciência ocidental em questões nativas e visões de mundo, assim contribuímos com um diálogo de uma Geografia mais equitativa.

Palavras-chave: Famílias Manchineri, Migrações, Fronteiras, Territórios.

\begin{abstract}
This work describes the lives of the migrants' families of Machineri people, highlighting specifically the migrations' network, the borders and the territories. We intentionally show how the migrated indigenous families were obligated to constitute and build new characteristics of survival in the occidental world, as well as new territorialities in different territories in new zones and categories and divide themselves into unknown and invisible places. Therefore, the main goal has been the comprehension of how the migration circle has been perpetuated, their many territorialities in triple border, as well as their regress to their villages, their hometown. This way, the indigenous migrations are showed in two manners, the circle ones and the linear ones. The circle ones happen when the families leave their village and return later; the linear ones happen when the families leave their village, and they do not return, but they still have parents and relationship in their hometown. These two kinds of migration are the most basics to the comprehension of what is indigenous mobility, obligated or free. What we should take in consideration it is the time of migration, the fact and the family history. The intention in this occasion is to guarantee the voices of the interviewed ones during the whole process of writing and comprehension of the article. Machineri people live in the Department of Pando (BOL), Department of Madre Dios (PE) and in the Brazilian city of Assis Brasil, State of Acre, in Mamoadate's Land, Cabeceira do Acre's land and Seringal Guanabara, and other locations in the urban zone in the three countries. As a methodological practice, we took the oral history, the interviews and the life experience of each interviewee; this way, we participated in their daily lives and the realities of their survival. This work aims to write in about the indigenous migration, indigenous borders and indigenous territories in the discussions of contemporary Geography as a way of contributing to new discussions inside and outside the academy, only this way we can have an intercultural discussion in the academy and to all society. Thereby, we take in consideration that the studies of indigenous questions need with urgency gain spotlight in the actual conjecture of political geography, as so that their indigenous lands are always fighting when it is related to the exploration of natural resources. This scene shows us how much these people are always fighting to guarantee their way of living and their traditional land, as so that today they suffer from a regression of the accomplishment and rights of indigenous people. It is necessary to study the migration of indigenous people inside the geography as a way of approaching this occidental science in fundamental questions and world views; thereby we contribute with a dialogue to equitable geography.
\end{abstract}

Keywords: Manchineri people, migrations, borders, territories. 


\section{CONSIDERAÇÕES INICIAIS}

O presente artigo tem com finalidade discutir questões como Migrações, Fronteiras e Territórios de famílias Manchineri que residem na fronteira que compõem o Brasil, Peru e Bolívia, as quais estão entrelaçadas com relações de parentesco e amizades. Deste modo, a análise visa especificamente compreender como se perpetuam essas migrações nas diversas configurações de territorialidade da/na Tríplice Fronteira dos países mencionados anteriormente.

O povo Manchineri vive no Departamento de Pando (BOL), Departamento de Madre Dios (PE) e em território brasileiro na cidade de Assis Brasil, Estado do Acre, na TI Mamoadate, TI Cabeceira do Acre e Seringal Guanabara.

Assim, as migrações indígenas são entendidas de duas maneiras, as circulares e as lineares. As circulares ocorrem quando a família se retira de sua terra de origem e retorna; já as lineares acontecem pelo fato da família afastar-se de sua terra de origem e não retorna, porém continua com a redes de parentesco e amizade com o local de origem. Esses dois modos de migrações são as mais básicas para a compreensão do que é a mobilidade indígena, seja ela "forçada" ou livre. O que devemos levar em consideração é a hora de migrar.

No estudo intitulado "Os eixos de Integração e Desenvolvimento e a Amazônia”, Becker (1999) considera que nossa região foi intensamente afetada pela "malha programada", em decorrência da riqueza de seus recursos naturais e à sua extensão aliada a baixas densidades demográficas, cuja ocupação tornou-se prioritária e estratégica à exploração econômica. Deste modo, compreendemos que a implantação da malha, ocorreu de modo rápido e violento, com isso, configurou a região como grande fronteira de recursos nacional e internacional, com grandes repercussões e transformações sociais e territoriais. Situações como essa levaram muitas famílias de indígenas a migrarem para lugares distantes de suas terras de origem.

Além disso, as famílias que migraram foram obrigadas a constituir e construir novas características de sobrevivência no mundo ocidental, bem como novas territorialidades em distintos territórios em novas zonas e categorias, e se "distribuírem” em recintos desconhecidos e invisíveis.

Ao mesmo tempo, os territórios indígenas são entendidos como parte integrante do social e pessoal indígena, são componentes construídas para si e para sua comunidade coletiva, e se tornam espaços de abrigo, segurança e poder para garantir sua sobrevivência. Diante desse assunto, surgem temas como "fronteiras" sociais e humanas para tais famílias de migrantes.

Deste modo, é necessário entendermos como são formadas essas fronteiras imaginárias e sociais nas concepções indígenas, no seu modo de vida. Diante dessa discussão, parafraseamos Martins (2009) que nos faz refletir e nos leva a acreditar que a fronteira é uma construção histórica, onde se mostra a cena da morte, do encontro e desencontro, dos conflitos e da alteridade. Assim 
entramos na questão indígena para discutirmos migrações, territórios e fronteiras em escala gradual, mas também de modo sintetizado e que possa dar sobretudo vozes a essas famílias de migrantes. $\mathrm{O}$ autor assim afirma que a "fronteira depende de uma incorporação desse conflito em suas complexas e até misteriosas formas como a referência mais relevante da pesquisa cientifica, coisa que raramente a ciência tem feito" (MARTINS, 2009, p.13).

Isso significa que como pesquisadores/as precisamos aprofundar e embrenhar-se em estudos sobre fronteiras em territórios/terras indígenas, devemos nos mover para o interior da discussão, do conflito, conhecer a desordem e suas motivações, sobretudo precisamos desencadear sobre os novos rumos das discussões sociais sobre fronteira, e é assim que devemos realizar estudos sobre os cenários indígenas, e como afirma Martins (2009) estudar "sobre a difícil diversidade de concepções do gênero humano".

No que tange aos territórios dialogamos como autores como Raffestin (1993, p.143), o qual afirma que "espaço e território são termos equivalentes. Neste sentido é essencial compreender bem que o espaço é anterior ao território, e assim o território se forma a partir do espaço, é o resultado de uma ação conduzida por um ator sintagmático em qualquer nível”. Destarte, os territórios indígenas nos últimos anos têm se tornado resultado de diversas ações, não somente interna, mas ações da sociedade envolvente com desejo de explorar e expandir o capital em terras tradicionais, de modo a acelerar a mobilidade e o processo de desterritorialização e transterritorialização.

Neste aspecto, Haesbaert (2012) considera que o território é o resultado da reordenação do espaço, cuja ordem implica na busca e no desenvolvimento de sistemas informacionais operacionalizados pelos homens, enquanto agente pertencente à uma cultura. No nosso entendimento sobre território indígena vemos que se constitui de uma ordem dinâmica que implica no encaixedesencaixe-reencaixe comandado pela territorialização e desterritorialização dos indivíduos na imaginação geográfica; como decorrência surge "invenções” e representações espaciais e sociais no interior das relações e das formações de pessoas, entre elas a das pessoas indígenas que tem uma dimensão do poder sobre o território que é totalmente diferente do pensamento ocidental.

As questões de famílias Manchineri entra no presente ensaio com um estudo de caso, que precisa ser apontado de modo peculiar e visível. Assim se faz necessário entender as tessituras e imbricações dessa coletividade que migra em área de fronteira. O difícil acesso, a difícil comunicação, e as dificuldades vividas entre cada unidade familiar. Ninguém migra sem uma rede de apoio de amizade e de parentesco. O ponto de partida veio como caminho por meio do diálogo e a compreensão que são as redes migratórias coletivas Manchineri.

A priori as famílias migram por algum motivo seja político, social ou econômico, com a finalidade de estudar, participar do movimento indígena e assim seguem a rota migratória. Dessa maneira, o artigo foi distribuído em três itens 'Histórico de famílias que migraram na década de 1980', 
'As fronteiras sociais ‘construída' nas cidades', e 'Famílias que retornam para suas terras de origem'. Estes itens que descrevemos são relatos da realidade social e geográfica de famílias originárias do povo Manchineri.

\section{FAMÍLIAS MANCHINERI QUE MIGRARAM NOS ANOS 1980}

Para os povos indígenas do Estado do Acre, a abertura dos seringais, iniciada a partir das últimas décadas do século passado, trouxe as correrias, expedições armadas organizadas pelos primeiros patrões nordestinos e pelos caucheiros peruanos. Estes violentos confrontos resultaram no elevado número de mortes, na introdução de doenças até então, inexistentes, assim como na dispersão dos membros das populações indígenas pelas cabeceiras dos principais rios da região. Data também desta época, a formação de uma ideologia que concebia o índio como brabo, que podia ser morto como qualquer outro animal perigoso da floresta (IGLESIAS; AQUINO, 1995, p.3).

Com essa dinâmica houve a inserção das populações indígenas na economia regional que iniciou a partir da década de 1910 retratada por Iglesias e Aquino (1995) "quando os preços da borracha internacional e as consequências transformações econômicas e comerciais da empresa seringalista impediram que os patrões continuassem importando mão-de-obra do nordeste do Brasil”. Começa aí uma nova etapa, de como "agregar" as populações originárias como mão-de-obra barata nos barracões, para tanto, foram dominados e discriminados no interior dos seringais e localmente passaram a ser conhecidos regionalmente como caboclos.

Decorridas aproximadamente seis décadas e com a crise da borracha, em 1972 a 1975 começa a luta pela demarcação das terras indígenas no Acre. Várias lideranças e caciques começaram suas "primeiras" reuniões nas aldeias e nas cidades, pois naquele momento inexistiam quaisquer atuações dos governos estadual e federal nas questões sobre as terras dos povos originários.

A situação apresentava-se crítica ao ponto de nos anos 1970 no Acre ser representado e concebido como o local que não existia mais povos originários, como aponta Txai Terri Vale de Aquino (1977) que todos os indígenas ali viviam eram considerados caboclos e agregados nos trabalhos dos patrões dentro dos seringais, e as mulheres como domésticas e quando não se eram agregados aos patrões, eram assassinados de maneira cruel. Muitas crianças e mulheres foram massacradas nas chamadas correrias como descrito pelo autor.

Iglesias e Aquino (1995) também afirmam que até a década de 1970 "os órgãos governamentais e importantes segmentos da sociedade desconhecia a existência de populações indígenas em terras acreanas". De fato, como a forte dominação dos patrões os povos originários ou indígenas ainda estavam juntos nos trabalhos dentro dos seringais, sem conhecer quaisquer de seus direitos.

A partir dos anos 1970, as lideranças passaram frequentar Rio Branco para exigir a demarcação de suas terras indígenas. Em encontro com a indigenista Vera Olinda (2014), esta afirma 
que a maior parte das lideranças só migraram para as cidades por conta da luta pela terra indígena e a formação e fundação de suas respectivas organizações.

Além disso, em entrevista, José Severino da Silva Manchineri (2019) recorda que antes da luta pela demarcação da terra, muitos do seu povo foram obrigados a se tornarem extratores de seringas, também faziam batida (limpeza de terrenos) nos campos e trabalhos nos seringais. Muitos eram enganados, pois não sabiam contar. Ele por exemplo, não era ludibriado já que conhecia a matemática, mas lembra que dava várias voltas na mata para marcar as seringueiras até o entardecer.

Todo o trabalho nos seringais era estabelecido pelos patrões e seus representantes; esses agentes iludiam os indígenas na hora de pesar a borracha, e também fazia "pagamentos" com a famosa cachaça, o que propiciava e incrementava o alcoolismo dentro das culturas originárias. Daí surge a forte presença de bebidas alcoólicas em muitas comunidades e que persistem até hoje no Acre, já nas fronteiras isso ocorreu devido à presença e influência dos caucheiros peruanos e bolivianos.

Depois de toda essa dinâmica exploratória, teve a chegada de indigenistas no Acre, e o esclarecimento sobre os direitos e luta dos povos indígenas; começa então a luta e organização para as demarcações de terras, processo esse que levará muitas famílias a deslocar-se com a finalidade de conquistar suas terras tão sonhadas, com isso sua libertação em relação aos patrões exploradores.

Impulsionado pela luta de conquistar suas terras, muitas lideranças tiveram que passar meses fora de sua vida tradicional, de suas mulheres e filhos. Seu José Severino da Silva (2019) nos disse que passava em média 40 dias longe de sua família, e que a mesma sempre ficava no antigo seringal Petrópolis. Quando retornava, levava sua vida normal como mateiro, e assim seguia a rotina do trabalho braçal nos antigos seringais.

Depois de muitas conversas com indigenistas e lideranças do Povo Jaminawa, escolheram uma área que se tornaria a Terra Indígena Mamoadate, com uma extensão de 313.647 mil hectares, regularizada em 1975. Em 1983 chegou na TI Mamoadate Sebastião Piro e seu filho Jaime Lhulu, depois de dois meses de navegação em barco, eles saíram do baixo Madre Dios para o Mamoadate (Brasil). A finalidade de Sebastião foi que sua mulher era Manchineri do Brasil e veio com o objetivo de visitar seus familiares. Jaime Lulhu Manchineri (2014) recorda que ele se encantou por uma menina no Mamoadate, casou-se e passou a residir em terras brasileiras.

Esses laços de parentesco, marcados por casamento, dentre esses tem-se o de Maria Monteza Manchineri (2018) esposa de um indígena boliviano do qual tem uma filha; os demais filhos dela são provenientes de outros relacionamentos antes de sua migração da TI Mamoadate para a TI Cabeceira do Rio Acre.

Na Comunidade Nativa da Bélgica na Bolívia encontramos parte da família da Jessica Jaminawa (2016) que durante nossa permanência na cidade de Assis Brasil (Acre) disse que sua família é uma mistura de Jaminawa com Manchineri que moram no lado boliviano, pois sua mãe acha 
melhor, por conta do esposo que é Yine da Bolívia e a comunidade fica próxima as cidades brasileira e boliviana. Deste modo, se constata a existência de migrações étnicas entre os três países fronteiriços, o que em muitos casos a união se realiza por grau de parentesco e pela língua - embora em cada um dos países sejam conhecidos como povos étnicos com nomes distintos.

Devido às diversas dinâmicas de famílias e mesmo em prol da luta político-territorial, a formação das organizações indígenas se deu pelo movimento político étnico no Acre, a qual é marcada por essas mobilidades. José Severino da Silva (2019) que foi cacique entre o povo Manchineri, após a demarcação teve que migrar junto com a família para Rio Branco-Acre nos anos 1980, o primeiro motivo foi que sua esposa precisava de tratamento de um câncer, o segundo devido sua contribuição na luta dentro do movimento indígena regional e posterior sua luta em âmbito nacional.

Esse foi o caso da maioria das lideranças dos anos 1970 e 1980. Sair de suas aldeias foi necessário, lutava-se pela terra e também pelos povos que ainda não havia conquistado esse direito territorial. Assim dão sequência das migrações para a capital acreana.

No ano de 1985 seu José Severino (2019) junto com sua família de sete filhos, muda-se definitivamente para Rio Branco, a princípio a cidade era rústica quase sem povoamento, quase sem carro e as grandes casas que haviam era na maioria dos antigos donos dos velhos barracões nas margens dos rios amazônicos.

A maioria da população era desprovida de recursos econômicos e de baix a estatura, não tinha mercado de trabalho para indígenas e nem mesmo para os "cabocos" da cidade que recentemente também tinha abandonados os barracões, ou porque tinha contraído a hanseníase vulgarmente chamada de lepra. Dá-se aí o processo de transição de morar na cidade, onde não há esperança de emprego, o jeito foi se organizar dentro do movimento indígena e buscar recursos estrangeiros.

Com a presença de indígenas de vários povos, começou a formação do Núcleo de Cultura Indígena, e com essa os trabalhos sobre questões que envolvem os povos originários do Acre e Sul do Amazonas.

Com isso a chegada de mais famílias indígenas, em 1986 por exemplo a família de Senhor João Cascudo Manchineri (2014) à Rio Branco com a finalidade de seguir os passos do José Severino. Porém ao chegarem na cidade não encontram notícias sobre a família do 'Zé', e começam uma saga de desencontro e à procura por emprego, a saída encontrada foi de trabalhar como caseiro nas chácaras para assim manter sua família.

Logo após chega à família Alves Rodrigues, que após o assassinato do patriarca Francisco, a matriarca dona Cândida resolveu sair da Terra Indígena Mamoadate. Cândida Rodrigues (2014) nos disse que saiu da aldeia em decorrência de conflitos que algumas famílias tinham com ela por conta 
de gado, e para evitar maiores dissabores resolveu abandonar definitivamente a aldeia e até hoje não retornou e não tampouco pretende fazer novamente.

Nos anos de 1994 a 1995 é a vez de alguns membros da família Samãrra Manchineri que migram com a finalidade de trabalhar não importa se seja braçal, o importante é se manter na cidade e juntar dinheiro para comprar um imóvel. Em relato, Francisco Samãrra Manchineri (2001) afirmou que trabalhou na descarrega de mercadorias dos barcos quando esses chegavam às margens do rio Acre, e assim ganhou sua vida na cidade; além disso conheceu sua esposa Maria, da etnia Kaxinawa, com quem tem filhos e agora possuem uma nova vida na cidade.

Entre os anos de 2009 e 2010 Lucas Arthur Brasil Manchineri e sua família migram para a capital acreana; seu objetivo era o de estudar e trabalhar na Comissão Pró-Índio do Acre. Ele, Lucas graduou junto com outros Manchineri na Licenciatura Intercultural Indígena na Universidade Federal do Acre, e mais adiante se tornou o primeiro de seu povo a ter um diploma de Mestre pela Universidade de Brasília - UNB.

Deste modo, a trajetória destas famílias nos demostra o quanto foi complexo a luta e sobrevivência na cidade. A vida urbana para o indígena nunca foi fácil, todas essas pessoas tem um histórico de resistência para permanecer forte no meio das batalhas no espaço urbano. Entretanto, essas famílias são as principais responsáveis por garantir o acesso de indígena em muitas políticas públicas na cidade, o que implica na busca pela garantia de seus direitos constitucionais.

\title{
3. AS FRONTEIRAS SOCIAIS ‘CONSTRUÍDAS’ NAS CIDADES
}

\begin{abstract}
As fronteiras nacionais são fenômenos complexos, não se resumem a limites, divisas, tratados diplomáticos, nem podem ser simplificados como o lugar do narcotráfico e do contrabando. As fronteiras políticas são criações humanas, delimitadas e demarcadas sucessivamente de acordo com os processos de ocupação militar, demográfica, econômica, política e cultural que ocorrem nos territórios limítrofes. As fronteiras políticas têm variados sentidos construídos pelas populações locais que vivenciam a experiência das travessias e dos controles estatais. Do ponto de vista dessas populações fronteiriças, outras fronteiras sociais são construídas através do comércio fronteiriço, das redes de amizades, familiares, de namoros e casamentos que atravessam os limites políticos. Essas fronteiras não são estáticas, mas estão em constante movimento de redefinição e negociação (ALBUQUERQUE, 2009, p.159).
\end{abstract}

O item responde duas perguntas norteadoras, dos quais muitos não indígenas nos indagam.

Uma das dúvidas tem sido o que são fronteiras para os indígenas? Qual o seu significado?

Fronteiras são coisas dos brancos, que inventaram para separar a gente, e agora fica essa questão que se é indígena Jaminawa é, mas se nasceu na Bolívia é pela lei boliviano embora seja nosso parente, e assim nós ficamos separados (Liderança Jaminawa no Teatro Hélio Melo - Encontro de Povos Indígenas na Fronteira em Rio Branco/Acre). 
Ainda com dificuldade conseguimos construir uma discussão sobre fronteiras sociais que envolvem questões do pensamento indígena, trazemos para a ordem o debate sobre fronteiras autóctones dentro da universalidade da Geografia. Estudos como esses quase não possuem enraizamento nas concepções dessa ciência, e dificilmente encontramos abordagens e conceitos para dar andamentos em diversas pesquisas sobre os povos originários.

Nesta discussão entra o tema fronteira, não somente a geográfica, a física, mas as fronteiras sociais e humanas. Porque ao tratarmos de povos originários as discussões exigem outra ótica e dimensão. Pois quando vamos debater sobre o assunto, por exemplo dentro do campo geográfico, nos deparamos com a falta de referências para uma construção sólida do pensamento indígena, assim temos uma imensa dificuldade em encontrar subsídios, mas estudos sobre a universalidade em geral, o que torna um problema que precisamos solucionar como agentes construtores do pensamento e saber geográfico.

De modo analítico, afirmamos que a Geografia não possui uma tradição sobre estudos dos povos originários ou indígenas, é para isso que elaboramos esse item para contribuir nessa construção. Dentre os vários problemas conceituais encontramos a fronteira como um nó górdio, o que na afirmação de Martins (2009) essa deverá ser pensada não só em relação alteridade, mas também em relação às concepções culturais do limite do humano pelos distintos coletivos sociais e étnicos que encontram na fronteira pontos de atritos, os quais podem ser físicos, ideológicos e políticos e resultam involuntariamente em colisões entre a cultura da sociedade envolvente e os coletivos étnicos.

$\mathrm{Na}$ tentativa de explicar essa dinâmica de fronteiras sociais, os indígenas são vistos e descritos de diversas visões nas cidades, a maioria das vezes de maneira distorcida, inapropriada, desrespeitosa e preconceituosa.

Muitos autores os descrevem como "índios desaculturados", porém particularmente compreendemos que independentemente de onde estejam e vivam serão povos indígenas, visto que transportam suas identidades étnicas. A visão deturpada propicia a construção de fronteiras sociais nas cidades, a qual por seu turno criará novas categorias e classes nas dimensões espacial e urbana. Os indígenas ao chegarem em determinado território-urbano ou território-fronteira começa uma nova (re)construção de seu eu coletivo e do novo espaço que ocupará. Nessa nova dimensão espacial (re)cria um novo território-fronteira com o caráter de proteção e abrigo. A questão das fronteiras criadas dentro desse novo espaço parte das diferenças culturais e sociais das sociedades em questão e nas quais se encontram.

Das análises que fizemos percebemos que os indígenas são transformados em classes invisíveis e diminuídas como pessoas e cidadãos. Daí recria-se um complexo de inferioridade nos mais jovens, de modo a torná-los restrito e desistirem de conquistar seus direitos e ações das políticas públicas nas/das cidades. 
Embora a mobilidade nas cidades não tenha sido um processo recente, esses povos são vistos como novos paradigmas como pobres e periféricos pela sociedade "branca". Ao questionarmos sobre a mobilidade de muitos Manchineri residirem nas cidades, percebemos que muitos são jovens e que seu intuito é estudar e retornar às terras de origens. A princípio os mais "velhos" chegaram as cidades para tratamento de saúde, quando não, estão a trabalho em setores do governo do Acre (BR), em prol da saúde indígena, no movimento indígena e nos trabalhos de suas organizações nas fronteiras.

Uma das formas mais complexa é como enxergar as fronteiras sociais perpetuada a partir de diferenças culturais na sociedade ocidental. Essas são concretizadas em todos os âmbitos físicos que se possa imaginar.

A escola por exemplo tem sido palco na construção de fronteiras entre o nós (indígenas) e o eles (não indígenas). De acordo com Gerson Manchinery (2018), nas escolas do Município de Assis Brasil, se encontram muitos matriculados como Jaminawa e Manchineri, mas também peruanos e bolivianos, pois é uma cidade fronteiriça e multiétnica; apesar de "todos" frequentarem as mesmas escolas, são diferentes em traços, vestuários, culturas e inventários.

Devido a esse motivo o deslocamento acelerado e como diz Albuquerque (2009) "produzem uma pluralidade de fronteiras (políticas, jurídicas, econômicas, culturais e simbólicas) entre classes, etnias, gênero, nações e civilizações". Nesse âmbito dinâmico as fronteiras nacionais e sociais se tornam, como também são vistas, como marcos de diferenças culturais entre as populações locais e regionais que se encontram em situações fronteiriças, mas também como espaços privilegiados de contato e de trocas materiais e simbólicas. Esses marcos na definição de Almeida Silva (2010; 2015) são os “marcadores" e "demarcadores territoriais", os quais são plenos de representações simbólicas e de materialidades.

Neste sentido, se encontram as trocas culturais e de saberes, em que as pessoas se definem de acordo com suas culturas e saberes originam ambiguidades nas vivências em sociedade. Em Assis Brasil por exemplo, a praça principal no centro da cidade, quando estão os indígenas sentados em bancos na praça, a sociedade local passa distante, pois lá estão os "índios”. Ainda que frequentem os mesmos locais, mercados, festas e festivais são vistos como os "índios" que não sabem de nada. Assim, o processo de inferioridade também cria conflitos e divisões sociais, dos quais faz com que amplie o preconceito e racismo. A falta de lógica e conhecimento sobre os povos originários é imensurável. Neste sentido também, precisamos decolonizar a colonização nas fronteiras como também a ótica construída nas populações locais.

Já nas fronteiras que chamamos de fronteiras institucionais encontramos a falta de crédito ao refúgio e abrigo de indígena que necessitam de apoio governamental; casos esses são retratados na saúde indígena, em que Manchineri e Jaminawa que nasceram na Bolívia e no Peru não podem 
mais usufruir do mesmo atendimento e benefícios de indígenas do que aqueles nascidos em solo brasileiro. A recíproca é verdadeira ao se inverter as direções de deslocamento com essa finalidade.

Ao mesmo tempo que negligenciam a saúde e a vida dos povos originários nas fronteiras, faz com que os limites impostos seja um grande retrocesso e impeça a luta dos povos lá residentes. Nessa lógica entendemos que o confronto vem de fora como condição de fragmentar os povos, sua luta e história.

As fronteiras sociais criadas nos fazem repensar em como prevenir esses povos da violência e do processo de desterritorialização desenfreado, pois morar nas cidades em busca de formação e garantia de seus direitos não lhe fazem menos indígenas do que os demais que vivem nas aldeias. Outros aspectos a serem acrescentados são como são vistos dentro do contexto urbano, isto é, que os indígenas possuem muita terra para poucas pessoas, e que recebem salário do governo mesmo sem trabalhar, e que "índios" não produzem, passam o dia em suas redes.

Acreditamos num processo decolonizador dentro da própria geografia, para tanto, precisamos ter o conhecimento ou saber sobre a própria população estudada. Deste modo, é possível que possamos fazer e construir uma fronteira na perspectiva indígena com sua indagação e compreensão. Com isso temos um material recolhido, um aprendizado enquanto pesquisadores capazes de entender as diferenças sociais e as diferenças da consciência humana que nos remete às estruturas e modos de viver de cada povo na fronteira do humano.

Através dessas fronteiras temos que ter a percepção das temporalidades da história dos povos indígenas, pois os problemas surgidos nas fronteiras para as populações locais tem sido a sua expansão interna, e nela como afirma Martins (2009) “a epistemologia da ideologia do pioneiro”, pois é nela que se centra a versão de conquistador, um suposto herói de conquista de novas terras e negligencia toda uma história dos povos autóctones.

Ao discorrermos ainda sobre os Manchineri, conhecemos muitos que são "tímidos" ao estarem em salas de aulas, reuniões e participarem de eventos sobre a temática indígena. Percebemos também que os Manchineri não vendem seus artesanatos na cidade; isso é uma maneira de prevenir sua cultura contra a comercialização em massa. Também aprendemos que os Manchineri não vendem sua bebida sagrada (Kamalampi) na cidade, muito menos seus rapés. Algumas vezes fazem a aplicação do famoso sanango (um colírio para os olhos/medicina tradicional).

Seu José Severino (2019), diz que "hoje é muito comum os jovens se autodeclararem pajés, em seu tempo tinha todo um processo de aprendizado, e todo jovem que iria aprender era escolhido pelos mais idosos". Isto ainda nos faz repensar como uma nova fronteira social nas cidades exerce influência, pois muitas medicinas indígenas têm sido também massificadas com a ajuda de não indígenas que procuram "conhecer", e depois que conhecem passam a vender a cultura, o que no nosso ponto de vista é biopirataria. 
Daí surge outra questão criada a partir de falta de conhecimento que é a afirmação que as medicinas autóctones são drogas, e nesse sentido aumenta a venda do rapé sem o consentimento indígena e sem o esclarecimento e sua importância para doenças. Além disso são criados discursos que a "macumba do índio é boa", e que "os índios sabem fazer bruxaria para amarrar homem/mulher", tudo criado a partir de percepções negativas sobre a verdadeira ciência dos povos originários.

Assim, ficamos diminuídos apenas ao valor de um camuflado e que todo indígena deve retornar sua terra de origem. O que tem nos despertado muita atenção tem sido grande parte de mulheres que são incluídas ao mercado de trabalho apenas como empregadas domésticas, com isso são forçadas a aceitarem um baixo salário para sobreviverem na cidade e manterem seus filhos na escola. E quando não são "integradas" ao mercado de trabalho é porque são preguiçosas, esse tem sido o discurso difundido e perpetuado há séculos.

A perspectiva é entrar de modo positivo no mercado de trabalho, mesmo com uma ocupação temporária, assim se cria suas primeiras estruturas nos espaços percorridos, pois nas aldeias muitas vezes é difícil o acesso à educação e saúde, o que faz com que essa dinâmica seja gradualmente seguida e se tornem referência para outras famílias.

Devido a diversas pressões, muitas famílias acabam por retornar para suas terras de origem, pela falta de espaço de visibilidade, mas também existem aqueles que nasceram na cidade e que decidiram permanecer e tentar com todas as lutas reverter o espelho social que lhe foi criado como meio de apagar sua história de luta e resistência, pois compreendem que somente desse modo suas lutas se tornam visível diante da população que ao longo dos tempos negligenciou os povos indígenas e suas culturas.

\section{FAMÍLIAS QUE RETORNAM PARA SUAS TERRAS DE ORIGEM}

Durante todo um processo de mobilidade, algumas famílias tendem a retornar para as aldeias e um dos motivos tem sido a falta de estrutura e alto índice de desemprego principalmente para indígenas, pois na cidade muitos delas precisam se reinventar enquanto ser social e coletivo, além disso precisam construir novas configurações de territorialidade para sobreviver.

O centro urbano tem sido hoje um forte palco de mobilidade de povos e de culturas, mas as ações de governo não são adequadas e preparadas para essa demanda e muito menos possuem diretrizes claras para essas famílias. Muitos cansam de reivindicar a garantia de seus direitos, e decidem viver no "isolamento", longe das ações e espaço do governo, e isso os faz com que se desesperem e passem não conquistar seus objetivos, o que se configura no desfacelamento da dinâmica e no consequente retrocesso por parte da sociedade envolvente, de modo que caracteriza-se assim a falta de empatia e contemplação na luta social e econômica. 
Na Tabela 1 demostramos alguns dos povos que no ano de 2013 residiam em Rio Branco, que lutavam e lutam pela sobrevivência em espaços sociopolíticos, assim buscam suas visibilidades e direitos de cidadania.

Tabela 01 - Povos Indígenas que moram na Cidade de Rio Branco.

\begin{tabular}{lccc}
\hline \multicolumn{1}{c}{ Povo } & Quantidade & Povo & Quantidade \\
\hline Apurinã & 491 & Kaxarari & 06 \\
Huni Kui (Kaxinawa) & 278 & Arara & 06 \\
Manchineri & 81 & Kambeba & 04 \\
Shanenawá & 50 & Kaigang/Guarani & 04 \\
Jaminawá & 39 & Ashaninka & 04 \\
Yawanawá & 15 & Apolima Arara & 04 \\
Jamamadi & 13 & Kulina & 03 \\
Não sabe & 12 & Bakairi & 03 \\
Nawá & 07 & Total & $\mathbf{1 . 0 2 0}$ \\
\hline
\end{tabular}

Fonte: Dados CIMI (2012). Organizado por Alessandra Manchinery, 2019.

A Tabela nos propicia a entender como esses povos estão presentes na cidade, mesmo que negligenciados pelo censo do Instituto Brasileiro de Geografia e Estatística - IBGE, com mensuração das questões sociais, econômicas e políticas dos povos indígenas em nível estadual, de modo que nos restou obter os dados completos e concretos junto ao Conselho Indigenista Missionário - CIMI.

E ainda conforme CIMI (2012), muitos indígenas estão distribuídos em bairros periféricos alguns com renda e outros sem nenhum meio de subsistência para continuar a viver no centro urbano e manter os filhos na escola. Sentimos assim o abandono por parte do Estado, o que resulta como consequência que essas pessoas vivam em áreas de vulnerabilidade e ao difícil acesso a seus direitos constitucionais como cidadãos. A pesquisa em campo representa e possibilitou sabermos o quadro representativo de famílias Manchineri em Rio Branco e as motivações de morarem em área urbana, ainda que desprovidos de apoio governamental e da própria sociedade local.

Em 2014, por exemplo, percebemos uma crescente chegada de Manchineri para as cidades, assim como também seu retorno, uma vez que muitas famílias entenderam que essa seria a única maneira ao regressarem para sua terra de origem, ainda que nas aldeias as escolas atendem somente até o $8^{\mathrm{a}}$ ano do ensino fundamental. Uns dos motivos do retorno foi a falta de visibilidade na cidade e em parte devido à fraca atuação do Estado frente à problemática indígena, mas também a falta de mercado e principalmente a dificuldade de sobreviver em contexto urbano.

A família de Lucas Manchineri (Tabela 2), retornou para a aldeia porque sua filha será professora no ensino fundamental, a mesma é bilíngue, e somente estava na cidade para aprender sobre as diretrizes de educação. 
Tabela 2 - Povos Indígenas que moram na Cidade de Rio Branco.

\begin{tabular}{|c|c|c|c|c|c|}
\hline Nome (Chefe) & Bairro & Trabalha & Membros & Total & Motivação \\
\hline $\begin{array}{l}\text { Elza Severino da Silva } \\
\text { Manchineri (Yoka) }\end{array}$ & $\begin{array}{l}\text { São } \\
\text { Francisco }\end{array}$ & Sim & $\begin{array}{l}\text { Felipe, Pámela Manchineri Simão, } \\
\text { Marlon Manchineri (nasceram em } \\
\text { Rio Branco) }\end{array}$ & 04 & Estudar \\
\hline $\begin{array}{l}\text { Maria } \\
\text { Souza }\end{array}$ & Vila Acre & Não & Casada com Kaxinawá & 05 & Estudar \\
\hline $\begin{array}{l}\text { José Severino da Silva } \\
\text { (Tio Zé) }\end{array}$ & $\begin{array}{l}\text { Belo } \\
\text { Jardim }\end{array}$ & Sim & & 05 & Trabalhar \\
\hline $\begin{array}{l}\text { Maria Cândida Alves } \\
\text { Rodrigues (Tia Canda) }\end{array}$ & $\begin{array}{l}\text { Sobral } \\
\text { CE }\end{array}$ & Aposentada & $\begin{array}{l}\text { Sába Haji, Joana, } \\
\text { Ribamar, Tody, } \\
\text { Raimundo, Mina e Edinei, Chuva } \\
\text { e um neto }\end{array}$ & 07 & $\begin{array}{l}\text { Não indígena, } \\
\text { morou na } \\
\text { Aldeia } \\
\text { Manchineri, e } \\
\text { voltou à cidade } \\
\text { novamente }\end{array}$ \\
\hline João Severino da Silva & $\begin{array}{l}\text { Belo } \\
\text { Jardim }\end{array}$ & Sim & & 05 & Trabalhar \\
\hline Dina Manchineri & $\begin{array}{l}\text { Apolônio } \\
\text { Sales }\end{array}$ & Aposentada & & 05 & Trabalhar \\
\hline Eugles Manchineri & Placas & Sim & $\begin{array}{l}\text { Tem uma filha e é casado com uma } \\
\text { não indígena }\end{array}$ & 04 & $\begin{array}{l}\text { Veio morar } \\
\text { com a mãe }\end{array}$ \\
\hline Nego Manchineri & $\begin{array}{l}\text { Irineu } \\
\text { Serra }\end{array}$ & Sim & $\begin{array}{l}\text { Tem um casal de filhos, e é casado } \\
\text { com não indígena }\end{array}$ & 03 & Estudar \\
\hline $\begin{array}{l}\text { Zete Alves de Souza } \\
\text { Manchineri }\end{array}$ & $\begin{array}{l}\text { Irineu } \\
\text { Serra }\end{array}$ & Sim & $\begin{array}{l}\text { Não tem filhos e é casada com não } \\
\text { indígena }\end{array}$ & 02 & Estudar \\
\hline $\begin{array}{lr}\text { Francisco } & \text { Samarrã } \\
\text { Maimará } & \text { Manchineri } \\
\text { (Chico) } & \end{array}$ & $\begin{array}{l}\text { Ramal do } \\
\text { V }\end{array}$ & Sim & $\begin{array}{l}\text { Tem dois filhos e é casado com } \\
\text { Kaxinawá }\end{array}$ & 06 & \\
\hline Francisco Natico Matias & $\begin{array}{l}\text { Belo } \\
\text { Jardim }\end{array}$ & Aposentado & Tem cinco filhos e é aposentado & 07 & $\begin{array}{l}\text { Saiu da aldeia } \\
\text { por motivos } \\
\text { particulares }\end{array}$ \\
\hline $\begin{array}{ll}\text { Lucas } & \text { Brasil } \\
\text { Manchineri } & \end{array}$ & Estação & Sim & $\begin{array}{l}\text { Duas filhas e casado com } \\
\text { Manchineri }\end{array}$ & 02 & $\begin{array}{l}\text { Trabalhar na } \\
\text { CPI/AC }\end{array}$ \\
\hline Alana Manchineri & $\begin{array}{l}\text { Xavier } \\
\text { Maia }\end{array}$ & & $\begin{array}{l}\text { Filha de Manchineri com não } \\
\text { indígena }\end{array}$ & 02 & $\begin{array}{l}\text { Nasceu na } \\
\text { cidade }\end{array}$ \\
\hline $\begin{array}{ll}\text { Eulge } & \text { Arthur } \\
\text { Manchineri } & \end{array}$ & Placas & Sim & $\begin{array}{l}\text { Casado com não indígena, tem } \\
\text { duas filhas }\end{array}$ & 04 & $\begin{array}{l}\text { Veio com sua } \\
\text { avó morar na } \\
\text { cidade }\end{array}$ \\
\hline Jessé Manchineri & $\begin{array}{l}\text { Santa } \\
\text { Maria/Vila } \\
\text { Acre }\end{array}$ & Sim & Casado com não indígena & 02 & $\begin{array}{l}\text { Meio } \\
\text { acompanhar o } \\
\text { pai e não } \\
\text { voltou mais }\end{array}$ \\
\hline $\begin{array}{ll}\text { Jangle } & \text { Felipe } \\
\text { Manchineri } & \end{array}$ & $\begin{array}{l}\text { São } \\
\text { Francisco }\end{array}$ & Não & Mora com a mãe e tem duas filhas & 02 & $\begin{array}{l}\text { Nasceu na } \\
\text { cidade }\end{array}$ \\
\hline André de Souza Brasil & & Sim & $\begin{array}{l}\text { Casado com não indígena e não } \\
\text { tem filhos }\end{array}$ & 02 & $\begin{array}{l}\text { Veio } \\
\text { acompanhar os } \\
\text { pais e estudar }\end{array}$ \\
\hline $\begin{array}{l}\text { Alexandre de Souza } \\
\text { Brasil }\end{array}$ & $\begin{array}{l}\text { Baixada da } \\
\text { Habitasa }\end{array}$ & Sim & $\begin{array}{l}\text { Casado com não indígenas e tem } \\
\text { duas filhas }\end{array}$ & 04 & $\begin{array}{l}\text { Veio } \\
\text { acompanhar os } \\
\text { pais e estudar }\end{array}$ \\
\hline $\begin{array}{l}\text { Soleane de Souza Brasil } \\
\text { Manchineri }\end{array}$ & $\begin{array}{l}\text { Chico } \\
\text { Mendes }\end{array}$ & Não & $\begin{array}{l}\text { Mora com irmãos e tia. Tem duas } \\
\text { filhas }\end{array}$ & 06 & $\begin{array}{l}\text { Veio com seus } \\
\text { pais ainda } \\
\text { criança }\end{array}$ \\
\hline João Cascudo & $\begin{array}{l}\text { Ramal do } \\
\text { Amapá }\end{array}$ & Aposentado & $\begin{array}{l}\text { Mora com a esposa e seus } 3 \text { filhos, } \\
\text { além dos netos }\end{array}$ & 09 & $\begin{array}{l}\text { Motivo } \\
\text { particular }\end{array}$ \\
\hline $\begin{array}{l}\text { Nega Manchineri } \\
\text { Total de famílias }\end{array}$ & $\begin{array}{l}\text { Ramal do } \\
\text { Amapá }\end{array}$ & $\begin{array}{l}\text { Dona de } \\
\text { casa } \\
\mathbf{2 1}\end{array}$ & $\begin{array}{l}\text { Mora com seu esposo que é do } \\
\text { Povo Kaxinawá } \\
\text { Total de pessoas }\end{array}$ & $\begin{array}{l}04 \\
90\end{array}$ & $\begin{array}{l}\text { Veio com sua } \\
\text { mãe e seu pai. }\end{array}$ \\
\hline
\end{tabular}

Fonte: Dados CIMI (2012). Organizado por Alessandra Manchinery, 2019. 
Já outra família que retornou recentemente é a de Sabá Manchineri que trabalha com SAFIs (Sistemas Agroflorestais Indígenas) e também é professor na Aldeia Alves Rodrigues dentro da Terra Indígena Mamoadate. Outros Manchineri que durante alguns anos residiram em Cruzeiro do Sul/Acre foram porque estudavam no Campus Floresta da Universidade Federal do Acre, cursaram na primeira turma da Licenciatura Intercultural Indígena, depois de graduados regressaram para suas aldeias de origem como profissionais do magistério.

O retorno dessas famílias representa uma mobilidade circular, pois saíram de suas terras para migrarem em lugares longínquos e depois retornaram. Essa característica também representa uma afirmação de suas necessidades de se sentir seguro somente em seus lugares de origem, e a saída representou em parte uma espécie de fuga, mas que logo adiante se tornará uma nova configuração de fronteira social e de territorialidades.

Destacamos ainda que os povos originários primaram desde tempos imemoriais no processo de fortes mobilidades, se antes eram por conta das sazonalidades, hoje tem sido para adquirir saúde, educação e segurança em suas terras. Assim não existem tempos e temporalidades para migrar, pois a mobilidade também se tornou uma condição humana, dos quais muitos estão inseridos nos campos da geografia e no campo da geopolítica.

Diante disso entendemos que o papel indígena é transformar sua pauta e causa em diretrizes, em ações e políticas públicas, sobretudo, precisam assim serem vistos como pessoas na atual conjuntura desfragmentada e desmanchada pela esfera pública.

\section{CONSIDERAÇÕES FINAIS}

Ao procurarmos debater e apresentar uma questão nova para a academia a partir da ótica e do pensamento indígena compreendemos que alguns pontos merecem ser seguidos e apreciados. Necessitamos de pesquisadores que levem como pauta a discussão sobre fronteiras, migrações e territórios indígenas dentro da Geografia. A mesma preocupação deveria permear as demais áreas do conhecimento para que se complementem essa discussão inicial. É preciso ouvir, entender como os povos originários pensam o mundo e como podem contribuir para que possamos ter uma sociedade melhor.

Falar e estudar as questões indígenas não é fácil, e levar essa compreensão é mais difícil ainda, pois essa discussão tem sido na sociedade brasileira o lugar do incapaz, camuflado e selvagem, "o índio que pode/deve andar pelado"; nesses aspectos são produzidas liturgias cruéis da identidade indígena, assim como a segregação e violência com esses povos, sua história, sua ciência, suas espiritualidades e seus modos de vida. 
É indispensável rever a(s) História(s) que foram mal contadas e produzidas por pessoas que só veem e aplicam seus pontos de vista, pois tais fatos negligenciam experiências, vivências, geografias, sobretudo, conhecimentos que são importantes para a humanidade e à vida no Planeta.

Para "universalizamos" e difundirmos o pensamento indígena precisamos dar destaque a esses povos, a suas culturas, a suas políticas e as suas geografias, como condição de construir um novo paradigma de pensamento capaz de propiciar avanços. É da junção dos vários conhecimentos que podemos compreender essas questões que nos realizam e nos tornam mais críticos quanto à realidade de muitos povos que habitam nosso país e o mundo. Geografar entre outros povos é necessário, relevante e indispensável.

\section{REFERÊNCIAS}

ALBUQUERQUE, J. L. C. A dinâmica das fronteiras: deslocamento e circulação dos "brasiguaios" entre os limites nacionais. Horizontes Antropológicos, Porto Alegre, v. 5, n. 31, p. 137-166, 2009.

ALMEIDA SILVA, A. Territorialidades e identidade dos coletivos Kawahib da Terra Indígena Uru-Eu-Wau-Wau em Rondônia: “Orevaki Are” (reencontro) dos “marcadores territoriais”. 2015. 301 f. Tese (Doutorado em Geografia), Universidade Federal do Paraná, Curitiba, 2015.

. Territorialidades, identidades e marcadores territoriais Kawahib da Terra Indígena Uru-Eu-Wau-Wau em Rondônia. 1. ed. São Paulo: Paco Editorial, 2015. 298p.

AQUINO, T. T. V. Kaxinawá: de seringueiro a “caboclo" a peão "acreano". 1977. 111 f. Dissertação (Mestrado em Antropologia) - Universidade de Brasília, Brasília, 1977.

BECKER, B. K. Os eixos de Integração e Desenvolvimento e a Amazônia. Revista Território, Rio de Janeiro, v. 4, n. 6, p. 29-42, 1999.

CIMI - Conselho Regional Amazônia Ocidental. Indígenas em Espaço Urbano no Acre. Rio Branco, CIMI/AC, outubro de 2012.

HAESBART, R. O mito da desterritorialização: do "fim dos territórios" à multiterritorialidade. 7. ed. Rio de Janeiro: Bertrand Brasil, 2012. 396p.

IGLESIAS, M. P.; AQUINO, T. T. V. Processo de Regularização de Terras Indígenas e Organização Política dos índios no Estado do Acre (1975-1994). Rio Branco: Mimeo, 1995. 211p.

MARTINS, J. S. Fronteira: A degradação do outro nos confins do humano. 1. ed. São Paulo: Contexto, 2009. 188p.

RAFFESTIN, C. Por uma Geografia do Poder. Série Temas, volume 29, Geografia e Política. Tradução Maria Cecília França. São Paulo: Ática, 1993. 269p.

\section{ENTREVISTAS}

Cândida Alves Rodrigues - Rio Branco - Acre (2014). 
Francisco Samãrra Manchineri - Rio Branco - Acre (2001).

Gerson Manchinery (2018).

Jaime Lulhu Manchineri (2014).

Jessica Jaminawa (2016).

João Cascudo Manchineri - Rio Branco - Acre (2014).

José Severino da Silva, 'Zé Urias’ Manchineri. Rio Branco - Acre (2019).

Maria Monteza Manchineri (2018).

Vera Olinda. Rio Branco - Acre (2014).

Trabalho recebido em 10/07/2019

Trabalho aceito em 11/07/2019 